\title{
MONITORING YIELD FAILURE OF FERROMAGNETIC MATERIALS WITH SPONTANEOUS ABNORMAL MAGNETIC SIGNALS
}

\author{
Zhongchao Qiu, Weimin Zhang, Xia Yu, Yan Guo, Long Jin
}

Original scientific paper

Yield failure is a common failure mode of low carbon steels in practical engineering application, so detecting it timely and accurately is of great significance. Tensile tests were carried out under different loads which covered tensile elastic loads up to plastic deformation. Meanwhile, the normal components of spontaneous abnormal magnetic field, the $H_{p}(y)$ signals, were measured offline using the TSC-1M-4 type instrument. The correlation between the magnetic gradient $K$ and the tension load $F$ is discussed. The results show that the $H_{p}(y)$ signals, which change gradually from negative to positive, approach a straight line and have a unique zero-crossing point in the elastic stage, and the magnetic gradient $K$ fluctuates with the load increasing. However, the distribution curve of the $H_{p}(y)$ signals has a peak and a trough in the yield stage, and the Lüders bands appear and expand as strain increases. The phenomenon of magnetic polarity reversal appears so that the magnetic gradient $K$ changes from positive to negative, thus the mechanical state of the specimens can be judged from the magnetic gradient $K$.

Keywords: magnetic domain; magnetic polarity reversal; metal magnetic memory; residual compressive stress; yield failure

\section{Praćenje izostanka popuštanja feromagnetskih materijala spontanim abnormalnim magnetskim signalima} Izostanak popuštanja je uobičajena pojava kod nisko ugljičnih čelika u praktičnim inženjerskim primjenama pa je njegovo pravovremeno i točno otkrivanje od velike važnosti. Vlačni pokusi su se provodili pri različitim opterećenjima, od vlačnih elastičnih opterećenja do plastične deformacije. U međuvremenu, normalne komponente spontanog abnormalnog magnetskog polja, $H_{p}(y)$ signali, mjereni su samostalno, instrumentom tipa TSC-1M-4. Razmatrana je korelacija između magnetskog gradijenta $K$ i opterećenja zbog vlaka $F$. Rezultati pokazuju da se $H_{p}(y)$ signali, koji se postepeno mijenjaju od negativnih do pozitivnih, približavaju ravnoj liniji i imaju jedinstvenu točku presjeka nultog izlaznog napona (zero-crossing point) u stadiju elastičnosti, i magnetski se gradijent $K$ mijenja s porastom opterećenja. Međutim, krivulja raspodjele $H_{p}(y)$ signala dostiže vrhunac kod granice popuštanja i kako se povećava deformacija pojavljuju se i šire Lüders pojasi (Lüders bands). Javlja se fenomen promjene magnetskog polariteta tako da se magnetski gradijent $K$ mijenja iz pozitivnog u negativni te se mehaničko stanje uzoraka može odrediti prema magnetskom gradijentu $K$.

Ključne riječi: izostanak popuštanja; magnetsko područje; promjena magnetskog polariteta; magnetska memorija metala; zaostalo tlačno naprezanje

\section{Introduction}

At present, the mechanical state of engineering components and structures in service needs to be detected correctly and timely, which has become a focus in the field of non-destructive testing. Yield failure is a vital criterion to judge whether the components can work normally. Because of their beneficial mechanical properties, ferromagnetic materials, expecially low carbon steels, are widely applied in fields, such as railway, pipeline, vehicle, ship, power station and aerospace. The stress-strain curve of low carbon steel specimens presents a serrated flat region in the yield stage, and the localized plastic zones, namely the Lüders bands, arise in the stress concentration zone. The appearance of the Lüders bands depends not only on the testing variable, but the heat treatment and microstructure parameters, such as grain size and dislocation density [1]. Components can be removed from service before there is any likehood of failure in case catastrophic accidents occur.

Magnetic techniques are most important NDT technologies to characterize the mechanical features of ferromagnetic materials based on the physical principle of stress-magnetic coupling effect, which consist of magnetic flux leakage (MFL), magnetic Barkhausen noise $(\mathrm{MBN})$, magnetoacoustic emission (MAE) and recently developed metal magnetic memory (MMM) [2, 3]. The first three are ascribed to the active magnetic methods where an applied strong field is used as the stimulus, while the last one is passive, which is a more simple and effective NDT magnetic technique to meet the requirements in engineering. Metal magnetic memory technique $[4 \div 11]$, firstly proposed by Russian researchers in 1997, has been proved to be effective in characterizing the early damage of ferromagnets, especially the micro-damage due to local stress concentration. Under the effect of the earth field and mechanical load, the spontaneous abnormal magnetic signals are generated in the stress-concentration zones where the tangential components of the spontaneous abnormal magnetic field, the $H_{p}(x)$ signals, appear with a maximum value, and the normal components, the $H_{p}(y)$ signals, change polarity and have a zero value. If the load is removed, the magnetization state is still retained. The technique is so potential for diagnosing early damage that it has received a great interest worldwide in the recent years. It has been confirmed in previous studies that the smooth ferromagnetic specimen under stress will gradually produce magnetic ordered state, and there is a good correlation between the $H_{p}(y)$ signals and the stress. However, as a comparatively new test method, the physical mechanism of the metal magnetic memory technique is still unclear due to lack of deeper theotetical support. Furthermore, the real magnetic signals measured usually contain some interfering factors, for instance, the difference of demagnetizing field, micro structure distribution and heat treatment condition, leading to a serious distortion of test results and hence invalid conclusions $[12 \div 15]$.

The variation of the $H_{p}(y)$ signals during the plastic deformation stage has already been studied a lot, but little during the yield deformation stage $[16,17]$. It is very 
important to study the variation of the $H_{p}(y)$ signals in the yield stage since yield failure is the beginning of plastic damage. Tensile tests of low carbon steel sheet specimens were carried out under different loads which covered tensile elastic loads up to plastic deformation. When a predetermined load was reached, the specimen was taken from the holders and laid on the platform, then the $H_{p}(y)$ signals were detected offline. The variation of the $H_{p}(y)$ signals is analyzed and discussed in detail. At last, the mechanical state of the specimens can be judged from the correlation between the magnetic gradient $K$ and the tension load $F$.

\section{Experiment method}

The test material is Q235 low carbon steel, of which chemical composition is listed in Tab. 1. Q235 steel is used very commonly as mechanical parts in practical engineering components and structures.

Table 1 Chemical composition (wt\%) of Q235 steel
\begin{tabular}{|c|c|c|c|c|c|}
\hline Steel & $\mathrm{C}$ & $\mathrm{Si}$ & $\mathrm{Mn}$ & $\mathrm{P}$ & $\mathrm{S}$ \\
\hline $\mathrm{Q} 235$ & $0,14 \div 0,19$ & $0,12 \div 0,30$ & $0,30 \div 0,65$ & $<0,045$ & $<0,05$ \\
\hline
\end{tabular}

The geometry and dimension of the specimens are shown in Fig. 1. Their nominal thickness is $4 \mathrm{~mm}$. Prior to the testing, the specimens were heated to $650{ }^{\circ} \mathrm{C}$ and kept for $30 \mathrm{~min}$ in a vacuum heat treatment furnace, and then cooled naturally in the furnace. Then, the specimens were demagnetized by TC-50 demagnetization machine to eliminate the magnetism during processing, and ground to 1000 grit finish. The measured line, of which the length was $100 \mathrm{~mm}$, was marked on the surface of the specimen. There were 21 points with $5 \mathrm{~mm}$ intervals on the horizontal line chosen for the $H_{p}(y)$ signals measurement.

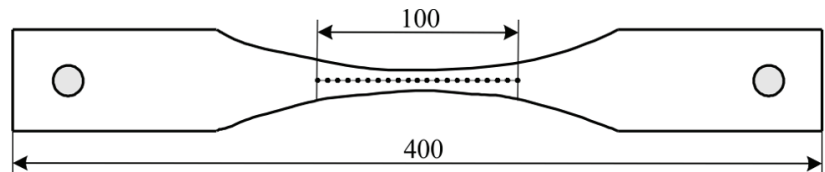

Figure 1 Specimen shape (in $\mathrm{mm}$ ) and measured points

In tensile testing, the $H_{p}(y)$ signals were measured by the TSC-1M-4 type instrument, and the variation of the specimen length $\Delta L$ was collected by a microcalliper. Specimen was firstly loaded to a predetermined stress, retained for some time and the variation of length $\Delta L$ was recorded, then the specimen was taken carefully from the grip holders and placed on a non-magnetic scanning platform along the south-north axis. Subsequently, the $H_{p}(y)$ signals along the measured line were collected. After measurement, the specimen was loaded again to a higher predetermined value, and the above procedures were repeated until the necking phenomenon appears.

\section{Experimental results}

According to the dependence of the variation $\Delta L$ on the tension load $F$, the specimen yielded when the load reached $15 \mathrm{kN}$, then necked when $20 \mathrm{kN}$, as shown in Fig. 2.

Once the specimen is fixed on the tensile machine, they will make up a large magnet, and the specimen is magnetized quickly. Thus, the initial state has a magnetic remanence inevitably, namely the initial remanence $H_{p 0}(y)$. In order to research the variation of the $H_{p}(y)$ signals caused only by the tension load, the initial remanence $H_{p 0}(y)$ is viewed as the reference magnetic field [18],

$\Delta H_{p i}(y)=H_{p i}(y)-H_{p 0}(y)$

where $\Delta H_{p i}(y)$ is the variation of magnetic signal caused only by the load and $H_{p i}(y)$ is the normal component of stress-induced magnetic field measured offline.

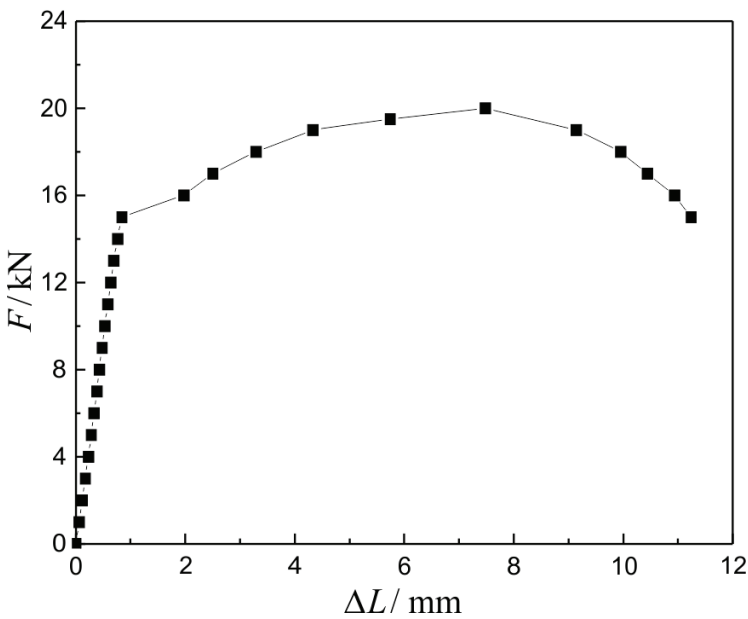

Figure 2 The dependence of the variation $\Delta L$ on the tension load $F$

The characteristics of the surface magnetic signals of every specimen are not indential, while their overall trends are consistent. In this paper, representative signals are taken for analysis. Fig. 3 presents the distribution of the $\Delta H_{p}(y)$ signals along the measured line under different loads. The $\Delta H_{p}(y)$ signals change apppropriately from $-200 \mathrm{~A} / \mathrm{m}$ to $200 \mathrm{~A} / \mathrm{m}$.

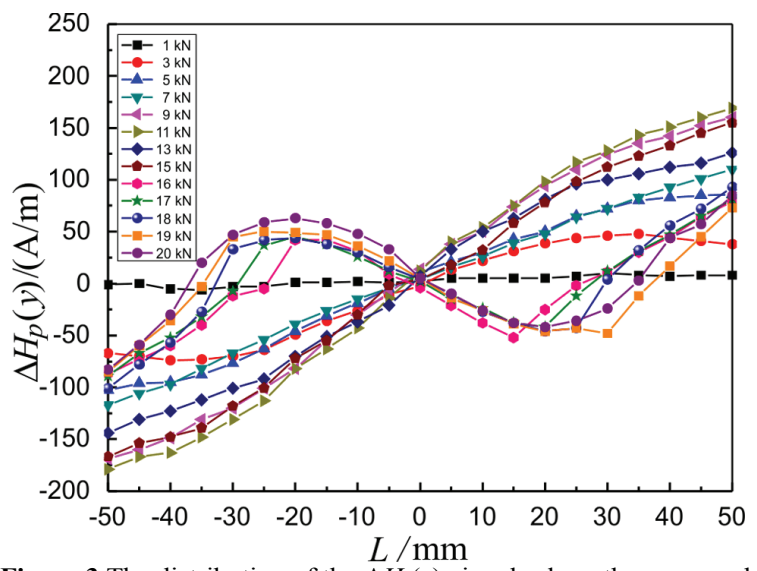

Figure 3 The distribution of the $\Delta H(v)$ signals along the measured line under different loads

Fig. 3 shows that the $\Delta H_{p}(y)$ signals have a zero value in the middle of the specimen where the smallest crosssectional area happens to be, which is consistent with stress concentration zone. In the elastic stage, the specimen is magnetized immediately due to the stressmagnetic coupling effect, and the $\Delta H_{p}(y)$ signals change gradually from negative to positive. The distribution of the $\Delta H_{p}(y)$ signals approaches a straight line, and has a 
unique zero value. However, the magnetic mechanism of the specimen is complex in the yield stage, and the $\Delta H_{p}(y)$ distribution presents the phenomenon of magnetic polarity reversal. The peak and the valley appear around $-25 \mathrm{~mm}$ and $25 \mathrm{~mm}$ respectively along the measured line and prone to the $x$-axis from the extreme to the ends of the specimen, owing to magnetic variation from the strong magnetic flux leakage region to the weak one.

In addition, the magnetized specimen is equivalent to a magnet, of which one end is $\mathrm{S}$ pole and the other is the $N$ pole.The distribution of the $\Delta H_{p}(y)$ signals at both ends is symmetric. Through the analysis of the two end points (the $1^{\text {th }}$ point and the $21^{\text {th }}$ point ) on the measured line, the magnetic field variation of the two points with load is shown in Fig. 4. The $\Delta H_{p}(y)$ signals change tendency of magnetic fields at the two points is contrary and symmetric about the line $\Delta H_{p}(y)=0$.

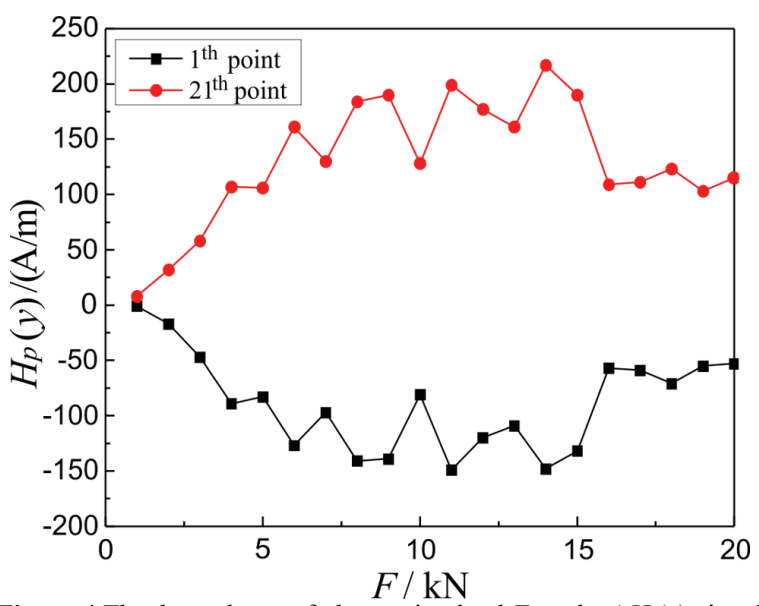

Figure 4 The dependence of the tension load $F$ on the $\Delta H_{p}(y)$ signal

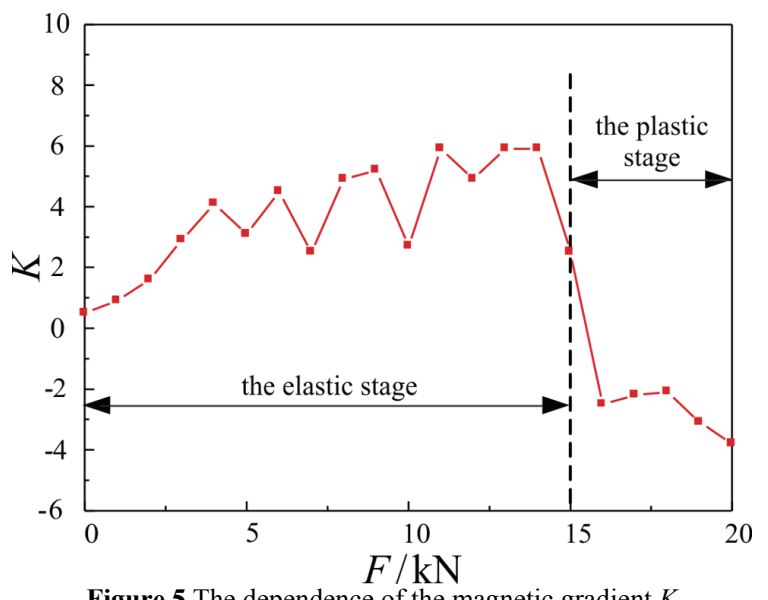

Figure 5 The dependence of the magnetic gradient $K$ on the tension load $F$

\section{Analysis and discussion}

The magnetic gradient $K$ in the middle of the specimen can be expressed as

$$
K=\frac{\Delta H_{p}\left(y_{12}\right)-\Delta H_{p}\left(y_{10}\right)}{2 \Delta x},
$$

where $\Delta H_{p}\left(y_{12}\right)$ and $\Delta H_{p}\left(y_{10}\right)$ present the $\Delta H_{p}(y)$ signals of the $12^{\text {th }}$ point and the $10^{\text {th }}$ point, respectively. $\Delta x$ is the interval of two adjacent points. Plastic deformation occurs mainly in the middle region about $10 \mathrm{~mm}$ while the other regions change little. Fig. 5 indicates the dependence of the magnetic gradient $K$ on the tension load $F$.

\subsection{The $\Delta H_{p}(y)$ signals of the elastic stage}

In the elastic stage, piezomagnetic effect changes the magnetic properties of ferromagnetic materials, orienting magnetic domains in the direction of the applied load. The movement of magnetic domains consists of three processes, the magnetic wall moving, the magnetic wall merging and the magnetic domain rotating. The specimen still remains in the magnetization state after it is unloaded, as the domains wall mergence and the domains rotation are not reverse. The variation of magnetic domains is consistent with the permeability change of ferromagnetic materials. From a mechanical perspective $[19,20]$, the stress energy is generated in tensile tests. When test temperature is far below the Curie point, the internal energy of ferromagnets can be determined by Eq. (3), provided that total free energy is equal to internal energy.

$$
F=F_{K}+F_{\sigma}+F_{d}
$$

Where $F_{K}$ is magnetocrystalline anisotropy energy, $F_{\sigma}$ is stress energy, and $F_{d}$ is demagnetization energy. When stress energy comes into being, corresponding magnetoelastic energy must be produced to offset it, so that the total free energy keeps to a minimum. The generation of elastic energy will change the position of domain walls, so the magnetization direction changes and magnetic flux leakage exists on the surface of the specimen [21].

Crystal slip occurs in ferromagnetic materials during the elastic stage due to the elastic imperfection. The movement of crystal slip needs a certain time owing to the process of energy accumulation. Corresponding stress energy can be released when the sliding motion occurs, so the $\Delta H_{p}(y)$ signals fluctuate as the load increases. The $\Delta H_{p}(y)$ signals shaking up results from the accumulation of the internal energy, while shaking down results from the release of internal energy after it reaches a certain threshold [22].

\subsection{The $\Delta H_{p}(y)$ signals of the yield stage}

The stress-magnetic coupling mechanism in the elastic stage is quite different from that in the plastic stage, and the latter is the main reason of material failure. Yield failure appears in the early plastic deformation stage, and the Lüders bands are localized regions of high plastic strain within a specimen, bounded by regions that have undergone mainly elastic deformation. Plastic deformation starts from the smallest cross-sectional area of the specimen once the stress reaches the upper yield point, and the microstructure is weakened quickly. If the load remains unchanged, plastic deformation can continue to a certain extent, so the stress concentration and the yield phenomenon, which appear at the junction of the deformed zone and non-deformed zone, furthermore expand gradually to the non-deformed area as the strain increases, as shown in Fig. 6. 
In the view of micro-structures in the ferromagnets, the magnetic properties of the ferromagnetic materials can be determined by the domain structure and its moving way. In the yield stage, the domains movement and rotation are affected by a lot of factors, of which the most important are dislocation pinning and residual compressive stress. Previous studies mainly concentrate on the prevention of dislocation pinning to the domains moving, while the effect of residual compressive pressure does not get much attention.

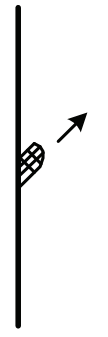

(a)

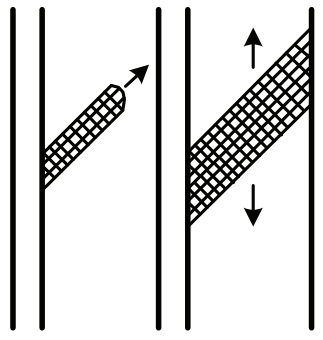

(b) (c)

Figure 6 The formation and expansion of the Lüders bands

Cottrell atmosphere forms in low carbon steels due to dislocation pinned by carbon atoms or hydrogen atoms. Dislocation can move after it grids rid of air mass in the plastic stage, and the upper yield point appears with the stress increasing. Once dislocation grids rid of air mass, the dislocation can continue at a low stress. The yield stage is the beginning of the dislocation movement, and the mechanisms between domain walls and isolated dislocations, dislocation tangles and dislocation cells are different. The yield stage mainly concludes isolated dislocation and a small amount of dislocation tangles, which can be overcome in the process of the domain wall moving. In a word, the effect of dislocation on the domain wall moving is quite weak and can be overcome during the yield stage.

a)

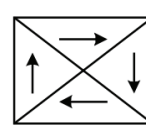

b)

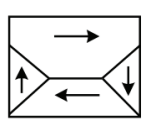

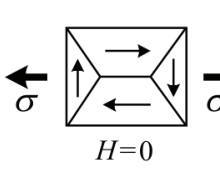

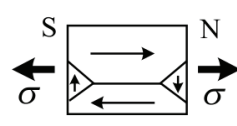

Applied magnetic field $H$

Figure 7 The effect of magnetic and stress on the movement of magnetic domains

In the plastic stage, the specimen produces residual compressive stress which affects the variation of magnetic domain structure, thereby leads to the variation of the surface magnetic field of the specimens. From the perspective of micromachanism, ferromagnetic materials are composed of numerous magnetic domains. Every domain is of the order of $10^{-8} \div 10^{-12} \mathrm{~m}^{3}$ in volume and consists of $10^{12} \div 10^{15}$ atoms. The magnetic moments distribute randomly in the initial state and no magnetization appears. When an external load is applied to a ferromagnetic specimen, a tension tends to orient the domains in the direction of the applied load for a positive magnetostrictive material and a compression orients the domains perpendicularly to the loading direction due to the piezomagnetic effect [23], as shown in Fig. 7. The domain structure is mainly at $180^{\circ}$ in the elastic stage while it is mostly at $90^{\circ}$ and a maze kind in the yield stage. The macroscopic parameters of ferromagnetic specimen, such as permeability $\mu$, would change along with the variation of magnetic domain structure, which has a vital influence on the $\Delta H_{p}(y)$ signals.

The permeability of ferromagnetic materials is not constant, but shows complex variation when they are placed in different external magnetic fields and loadings. According to previous research, Eq. (4) can be observed when ferromagnetic component is affected by a weak magnetic field and uniaxial stress [24]:

$\mu=\mu_{T}\left(1+\frac{b \cdot H}{\mu_{T}}\right)\left[a_{0}+a_{1}|\sigma|^{m} \exp (n|\sigma|)\right]$

where $\mu_{T}$ is the initial magnetic permeability relating to temperature $T, b$ is a constant relating to material properties, $H$ is magnetic intensity, $\sigma$ is stress, $a_{0}, a_{1}, m, n$ are coefficients depending on the direction and value of the applied stress. When the external magnetic field is constant, the effect of residual compressive stress on the permeability can be expressed as

$g(\sigma)=a_{0}+a_{1}|\sigma|^{m} \exp (n|\sigma|)$

Acquired by the derivation of Eq. (5)

$g^{l}(\sigma)=a_{1} \cdot e^{n|\sigma|} \cdot|\sigma|^{m-1}(m+n|\sigma|)$.

When the residual compressive stress $\sigma<m / n, g^{l}(\sigma)>0$, that the permeability $\mu$ increases with the stress increasing. When $\sigma>-m / n, g^{l}(\sigma)<0$, that the permeability $\mu$ decreases with the stress increasing. Thus, the magnetization reversal happens where $\sigma=-m / n$.

Meanwhile, the variation of the $\Delta H_{p}(y)$ signals can be well explained by the Jiles-Atherton-Sablik model. Based on the concept of "effective field theory" and "law of approach", the Jiles-Atherton-Sablik model for magneto-mechanical effect was presented by Jiles et al $[25,26]$. The magnetization caused by applied stress $\sigma$ is equivalent to a magnetic field $H_{\sigma}$ for a macroscopic polycrystalline multi-domain system:

$$
H_{\sigma}=\frac{1}{\mu_{0}} \frac{\partial E_{\sigma}}{\partial M}=\frac{3}{2} \frac{\sigma}{\mu_{0}}\left(\frac{\partial \lambda}{\partial M}\right)_{\sigma}\left(\cos ^{2} \theta-v \cdot \sin ^{2} \theta\right)
$$

where $\lambda, \mu_{0}$ and $M$ are the bulk magnetostriction constant, vacuum permeability and the magnetization, respectively.

According to Jiles et al., magnetostrictive coefficient $\lambda$ can be described as $\lambda=\gamma \cdot M^{2}$, where $\lambda$ is a coefficient related to the stress. Omitting its high-order term, $\lambda$ can be expressed as

$$
\gamma=\gamma_{11}+\gamma_{12} \cdot \sigma
$$


Likewise, the data of $\lambda_{11}$ and $\lambda_{12}$ are determined. $\lambda_{11}=$ $7 \times 10^{-18} \mathrm{~m}^{2} / \mathrm{A}^{2}, \lambda_{12}=7 \times 10^{-25} \mathrm{~m}^{2} / \mathrm{A}^{2} / \mathrm{Pa}[27,28]$.

Place the specimen in the north-south direction, ignore the geomagnetic declination, and assume that $\theta=$ 0 , then the effective field $H_{\sigma}$ can be described as

$$
H_{\sigma}=\frac{3 \gamma \sigma}{\mu_{0}} M=\frac{3 \sigma M}{\mu_{0}}\left(7 \times 10^{-18}-1 \times 10^{-25} \sigma\right) .
$$

In Eq. (9), magnetization $M$ can be taken as a positive constant owing to the specimen excited by the earth magnetic field. When $\sigma$ is the compressive stress $(\sigma$ $<0), H_{\sigma}<0$ stands regardless of the stress value. The equivalent magnetic field will be produced in the opposite direction of the geomagnetic field when the load is compressive. In the process of the Lüders bands formation and expansion, compressive residual stress is produced in the Lüders bands, and increases with the increasing deformation, which makes the magnetic field polarity reverse in the yield stage.

In addition, plastic deformation has a significant influence on microstructure. Crystal rotates when plastic deformation of polycrystalline occurs, and the original random orientation of each grain will adjust gradually each other converge, which is called the deformation texture. The texture makes the low carbon steel change from isotropic to anisotropic. The low carbon steel tends to produce [100] texture in the plastic stage, and the [100] direction is just the easy magnetization direction of ferromagnetic materials. When the axis of easy magnetization is in the same direction with the tensile stress, a large number of magnetic domains orient in the direction of stress-induced magnetization, which makes the magnetic field increase in the opposite direction of the initial magnetic field.

In a word, the main purpose of non-destructive testing is determining the mechanical state of the service test in terms of the detection results. As can be seen in Fig. 3, the specimen is in the elastic stage when $K>0$, while the specimen has entered the yield stage and yield failure occurs when $K<0$. Thus it can be judged whether the specimen has failed in terms of the magnetic gradient $K$, which is of significance for practical engineering application.

\section{Conclusions}

It is of great importance in modern industry to monitor yield failure in an engineering structure. Feasibility, easy-operation and flexibility to variable working environments are much preferred requirements, which are hard to achieve in most traditional nondestructive testing techniques. As a novel non-destructive testing technique, MMM technique provides great opportunity to meet the above requirements and can determine both applied and residual stress as well.

The $H_{p}(y)$ signals, which approach a straight line and have a unique zero value, change gradually from negative to positive in the elastic stage, and the magnetic gradient $K$ fluctuates as the tension load increases. However, the Lüders bands appear and expand as the strain increases in the yield stage, and the distribution curve of the $H_{p}(y)$ signals has a peak and a trough, respectively. The phenomenon of the magnetic polarity reversal appears, so that the magnetic gradient $K$ changes from positive to negative, thus the mechanical state of the specimens can be judged from the magnetic gradient $K$.

\section{Acknowledgements}

We would like to thank all the referees for their valuable comments in improving this paper. This research is supported by The Foundation of National Nature Science of China (Grant No. 51275048). Special thanks to the editors of Tehnicki vjesnik-Technical Gazette, reviewers and authors of referred papers.

\section{$6 \quad$ References}

[1] Dhar, A.; Clapham, L.; Atherton, D. L. Influence of Lüders bands on magnetic barkhausen noise and magnetic flux leakage signals. // Journal of Materials Science. 37, 12(2002), pp. 2441-2446. DOI: 10.1023/A:1015419018741

[2] Jiles, D. C. Review of magnetic methods for nonodestructive evaluation. // NDT International. 21, 5(1988), pp. 311-319. DOI: 10.1016/0963-8695(88)90001-1

[3] Wang, Z. D.; Gu, Y.; Wang, Y. S. A review of three magnetic NDT technologies. // Journal of Magnetism and Magnetic Materials. 324, (2012), pp. 382-388. DOI: 10.1016/j.jmmm.2011.08.048

[4] Dubov, A. A. A study of metal properties using the method of magnetic memory. // Metal Science Heat Treat. 39, 9(1997), pp. 401-405. DOI: 10.1007/BF02469065

[5] Dong, L. H.; Xu, B. S.; Dong, S. Y.; Li, S. ; Chen, Q. Z.; Wang D. Stress dependence of the spontaneous stray field signals of ferromagnetic steel.// NDT \& E International. 42, 4(2009), pp. 323-327. DOI: 10.1016/j.ndteint.2008.12.005

[6] Shi, C. L.; Dong, S. Y.; Xu, B. S.; He, P. Metal magnetic memory effect caused by static tension load in casehardened steel. // Journal of Magnetism and Magnetic Materials. 322, (2010), pp. 413-416. DOI: 10.1016/j.jmmm.2009.09.066

[7] Yao, K.; Wang, Z. D.; Deng, B.; Shen, K. Experimental research on metal magnetic memory method. // Experimental Mechanics. 52, (2012), pp. 305-314. DOI: 10.1007/s11340-011-9490-3

[8] Yang, E.; Li, L. M.; Chen, X. Magnetic field aberration induced by cycle stress. // Journal of Magnetism and Magnetic Materials. 312, (2007), pp. 72-77. DOl: 10.1016/j.jmmm.2006.09.019

[9] Leng, J. C.; Liu, Y.; Zhou, G. Q.; Gao, Y. T. Metal magnetic memory signal response to plastic deformation of low carbon steel. // NDT \& E International. 55, (2013), pp.42-46. DOI: 10.1016/j.ndteint.2013.01.005

[10] John, W. Wilson; Tian, G. Y.; Barrans, S. Residual magnetic field sensing for stress measurement. // Sensors and Actuators A. 135, (2007), pp. 381-387. DOI: 10.1016/j.sna.2006.08.010

[11] Roskosz, M.; Bieniek, M. Evaluation of residual stress in ferromagnetic steels based on residual magnetic field measurements. // NDT \& E International. 45,(2012), pp. 5562. DOI: 10.1016/j.ndteint.2011.09.007

[12] Yao, K.; Deng, B.; Wang, Z. D. Numerical studies to signal characteristics with the metal magnetic memory - effect in plastically deformed samples. // NDT \& E International. 47, (2012), pp. 7-17. DOI: 10.1016/j.ndteint.2011.12.004

[13] Dong, L. H.; Xu, B. S.; Dong, S. Y.; Chen, Q. Z.; Wang, D. Monitoring fatigue crack propagation of ferromagnetic materials with spontaneous abnormal magnetic signals. // International Journal of Fatigue. 30, (2008), pp. 1599-1605. 
DOI: 10.1016/j.jifatigue.2007.11.009

[14] Li, L. M.; Huang, S. L.; Wang, X. F.; Shi, K. R.; Wu, S. Magnetic field abnormality caused by welding residual stress. // Journal of Magnetism and Magnetic Materials. 261, (2003), pp. 385-391. DOI: 10.1016/S0304-8853(02)01488-9

[15] Leng, J. C.; Xu, M. Q.; Zhang, Z. J. Application of empirical mode decomposition in early diagnosis of magnetic memory signal. // J. Cent. South Univ. Technol. 17, (2010), pp. 549-553. DOI: 10.1007/s11771-010-0521-5

[16] Li, J. W.; Xu, M. Q. Influence of uniaxial plastic deformation on surface magnetic field in steel. // Meccanica. 47, 1(2012), pp. 135-139. DOI: 10.1007/s11012011-9424-2

[17] Masatoshi, Kuroda; Shinsuke, Yamanaka; Koji, Yamada; Yoshihiro, Isobe. Evaluation of residual stresses and plastic deformation for iron-based materials by leakage magnetic flux sensors. // Journal of Alloys and Compounds. 314, (2001), pp. 232-239. DOI: 10.1016/S0925-8388(00)01226-3

[18] Guo, P. J.; Chen, X. D.; Guan, W. H.; Cheng, H. Y.; Jiang, $\mathrm{H}$. Effect of tensile stress on the variation of magnetic field of low-alloy steel. // Journal of Magnetism and Magnetic Materials. 323, (2011), pp. 2474-2477. DOI: 10.1016/j.jmmm.2011.05.015

[19] Jiang, S. T.; Li, W. Condensed matter magnetic physics. Science Press, Beijing, 2003. (in Chinese)

[20] Dong, L. H.; Xu, B. S.; Dong, S. Y.; Chen, Q. Z.; Wang, D.; Yin, D. W. Effect of tensile stress and residual stress on the spontaneous stray field signals from the surface of $0.45 \% \mathrm{C}$ steel. // Chinese Journal of Mechanical Engineering. 20(6), (2007), pp. 29-32. DOI: 10.3901/CJME.2007.06.029

[21] Dong, L. H.; Xu, B. S.; Dong, S. Y.; Chen, Q. Z.; Wang, D. Variation of stress-induced magnetic signals during tensile testing of ferromagnetic steels. // NDT \& E International. 41, (2008), pp. 184-189. DOI: 10.1016/j.ndteint.2007.10.003

[22] Wang, X.; Chen, M.; Xu, B. S. Change of magnetic memory siganals during the tension-compression fatigue of $48 \mathrm{MnV}$ steel. // China Mechanical Engineering. 18(15), (2007), pp. 1862-1864.(in Chinese)

[23] Lindgren, M.; Lepistö, T. Effect of prestraining on Barkhausen noise vs. stress relation. // NDT \& E International. 34, (2001), pp. 337-344. DOI: 10.1016/S09638695(00)00073-6

[24] Дубов, А. А. Повышение надежности энергетических котлов ТЭС путем совершенствования методов технической диагностики поверхностей нагрева. Автореферат дисертации к. т. н. Москва, 1989.

[25] Li, L.; Jiles, D. C. Modified law of approach for the magnetomechanical model: application of the Rayleigh law to stress. // Magnetics IEEE transactions. 39, 5(2003), pp. 3037-3039. DOI: 10.1109/TMAG.2003.815882

[26] Lo, C. C. H.; Lee, S. J.; Li, L.; Kerdus, L. C.; Jiles, D. C. Modeling stress effects on magnetic hysteresis and Barkhausen emission using a hysteretic-stochastic model. // Magnetics IEEE transactions. 38, 5(2002), pp. 2418-2420. DOI: 10.1109/TMAG.2002.803612

[27] Chen, Y.; Jiles, D. C. The magnetomechanical effect under torsional stress in a cobalt ferrite composite. // Magnetics IEEE transactions. 36, 5(2000), pp. 3244-3247. DOI: 10.1109/20.908755

[28] Jiles, D. C.; Devine, M. K. The law of approach as a means of modeling the magnetomechanical effect. // Journal of Magnetism and Magnetic Materials. 140-141, (1995), pp. 1881-1882. DOI: 10.1016/0304-8853(94)00928-7

\section{Authors' addresses}

\section{Zhongchao Qiu}

School of Mechanical Engineering, Beijing Institute of Technology, Beijing 100081, China

E-mail: zhongchaoqiu@gmail.com

\section{Weimin Zhang, Professor}

School of Mechanical Engineering, Beijing Institute of Technology, Beijing 100081, China

E-mail: zhangwmbit@gmail.com

\section{Xia $Y u$}

School of Mechanical Engineering, Beijing Institute of Technology, Beijing 100081, China

E-mail: yuxiabit@gmail.com

\section{Yan Guo}

School of Mechanical Engineering, Beijing Institute of

Technology, Beijing 100081, China

E-mail: xingyunxiaomimi@gmail.com

\section{Long Jin}

School of Mechanical Engineering, Guangxi University of Science and Technology, Guangxi Liuzhou 545006, China

Email: jinlongguangxi@gmail.com 